\title{
That Feels Like Home: Connecting Sites of Lockdown to Design Collections
}

\author{
Zoe Hendon
}

The Museum of Domestic Design and Architecture (MoDA) is part of Middlesex University, London, UK. As a university museum, we are fortunate not to be reliant on commercial income, nor to have been required to furlough staff during the lockdown. Instead, our challenge has been to continue to make a genuine contribution to the life of Middlesex University and to the wider community while staff have been working from home, without physical access to the collections. University museums around the world have faced similar challenges. We are taking a pragmatic approach, thinking about what can be done while holding on to the museum's overall purpose. Specifically, we aim to empower people to learn through the cocreation of knowledge and engagement with MoDA's collections; in addition, we intend to build and sustain communities of interest around the collections by supporting, celebrating and promoting formal and informal learning. In the immediate context, we were able to adapt a previously planned program to stimulate audiences to think critically about the primary space they were occupying - home - and its role as a social and cultural construct.

Before COVID-19, access to our collections was via individual appointment or workshop sessions for small groups. We do not have public galleries, and in a sense this relatively limited access has been an advantage, because it has meant that in recent years we have paid attention to developing our online presence via our website and social media. Our aim has been to make the museum's website visually appealing and easy to browse, including catalogue records for individual objects, co-created content (responses by students, researchers and others to the museum's collections), and curated content on particular themes. ${ }^{1}$ We have deliberately designed the website to be a starting point for different kinds of learning, and we hope that users will find something interesting that will draw them to explore further, whether it is an advice book for women or a brochure for 1930s suburbia.

Pre-lockdown, museum objects, staff, and students would come together in physical space, but in the current context of social distancing it looks unlikely that we will be able to offer in-person object-based sessions for the foreseeable future. Our experience of COVID-19 has therefore been one of reimagining the kinds of online encounters we offer students and others. We have been talking to academic colleagues about how they might use MoDA's existing online resources creatively (and how we might develop new ones) through, for example, blended learning sessions that combine students' engagement with the website with online discussions and activities led by museum staff in 'real' time. More generally, our strategy has been to develop new content on our website, both as a way of satisfying our wider public audiences, and to show academic colleagues the kind of activity we could do with and for students. ${ }^{2}$

At the beginning of lockdown we considered collecting tangible objects related to COVID-19 but, after some deliberation, we decided that our limited resources would make this impossible. We do not have the physical space or the staff time to make COVID-19 collecting a meaningful exercise. In any case, we were reluctant to duplicate the efforts of other museums. Instead, we decided to contribute to the discussion around home life under lockdown through our podcast. The first series of our podcast, 'That Feels Like Home' (recorded pre-pandemic and broadcast February-April 2020) examined themes relating to homes and housing. We had begun to think about a second series, which we had planned to broadcast in early 2021. COVID-19 forced us to re-evaluate our plans: we brought the schedule forward, rethought the focus, and speeded up production so we could ensure that the content was relevant and current. 
The resulting second series (produced and broadcast between May and July 2020) consists of six episodes, each of which examines the effects of COVID-19 on shared experiences and perceptions of home. ${ }^{3}$ MoDA's curator, Ana Baeza, interviewed historians, anthropologists, activists and practitioners about the challenges brought about by COVID-19, with one or two guests per episode. Discussions centred around how COVID-19 affected our sense of home, the new ways in which we are engaging with others in our domestic spaces, the ways in which our relationship to home has been affected by new work routines, and the effects of lockdown on those who do not have a stable home. For example, one podcast discussed the irony that, while the lockdown appeared to present a retreat into privacy, Zoom meetings and similar technologies made homes more visible than ever.

Recording during lockdown presented the technical challenges of conducting interviews remotely, but the advantage was that we were able to invite more geographically dispersed contributors, since we were liberated from the requirement that they travel to the museum. This resulted in conversations in which academics from a variety of fields combined their research perspectives on the museum's collections with personal reflections on home life under lockdown. An example was the conversation between Lukas Engelmann, a historian of medicine, and Elizabeth Darling, an architectural historian, about cities, living conditions, and epidemics. Their far-ranging discussion included such topics as hygienic modernity, the role of nationalism in sanitation, theories of contagion, racism and structural inequality in epidemics, public health messaging, and the role of photography in constructing pandemics.

In the first series of the podcast, we had been able to use guests' physical engagement with objects from the museum's collections as the starting point for discussion. This was not possible for the second series because of the physical closure of the museum and the continuing requirement that staff work from home. Nevertheless, the themes of each episode were chosen carefully in relation to our collections. The intention was not to 'put the objects in historical context', but rather to use objects as a prompt for questions that are engaging in the present.

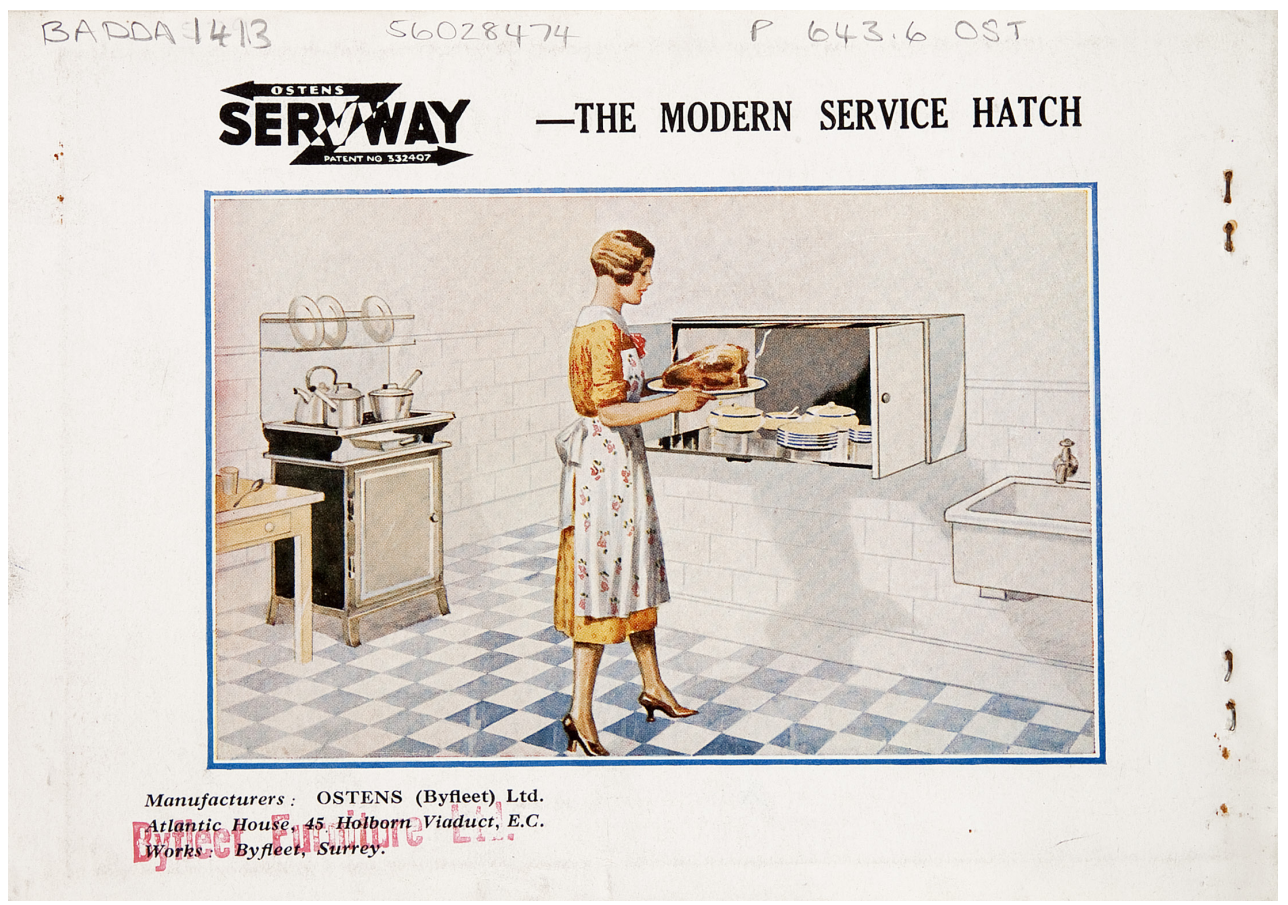

Fig 1. Ostens Servway: The Modern Service Hatch, catalogue by Ostens (Byfleet) Ltd, 1930-1940 


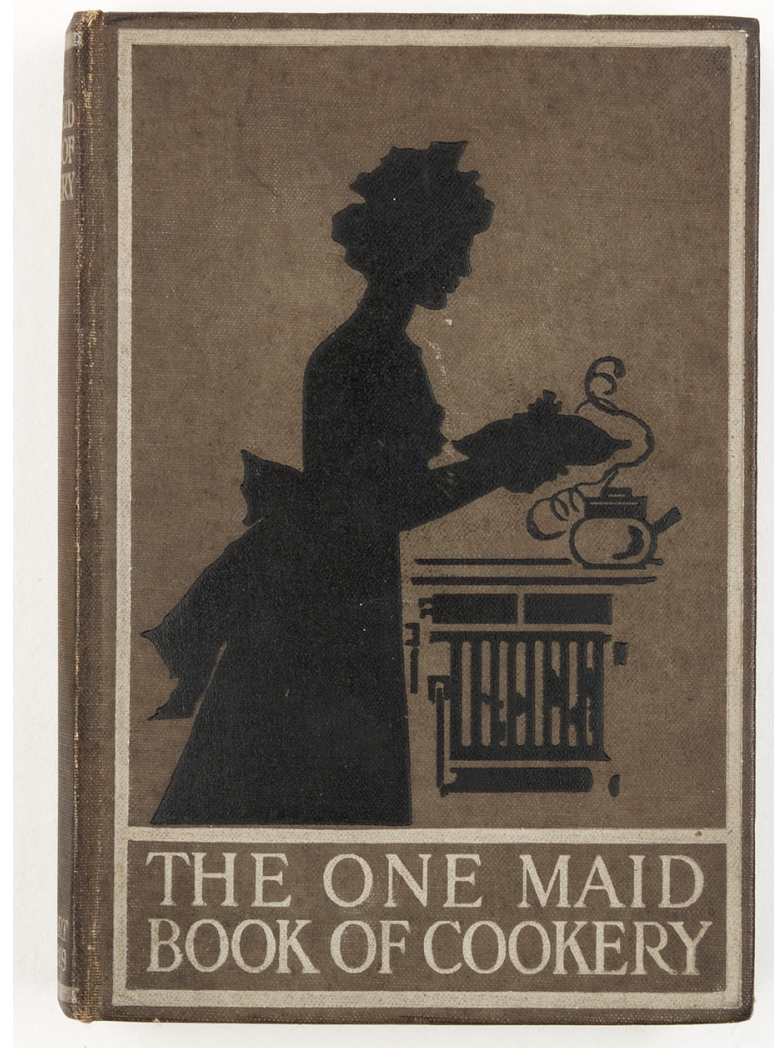

Fig 2. The One Maid Book of Cookery by Mistress A. E. Congreve, 1913.
For example, in Episode 5, 'Home Work/House Work', ${ }^{4}$ Ana Baeza used a brochure for the 'Ostens Servway Modern Serving Hatch', ${ }^{5}$ and a book entitled The One Maid Book of Cookery (1913), ${ }^{6}$ as the starting points for a discussion with Professor Rosie Cox (Birkbeck) and Dr Lucy Delap (Cambridge University). Their conversation ranged from historic and contemporary debates around the gendered division of housework to the issues surrounding paid domestic employment, and the problematic legal status of workers such as nannies and au pairs during the pandemic.

All the episodes of 'That Feels Like Home' are available on Apple podcasts/iTunes, Spotify, Tuneln, Stitcher and Google Podcasts. Each episode has its own page on the museum's website, where listeners can find a transcript, reading list, images and links to selected objects from the museum's collections. Reading lists include books and articles by guests, references to research in the field, and links to newspaper articles and websites. As a university museum, we are keen to ensure that podcast episodes may serve as teaching resources in future, and while we intend for each episode to appeal to a general audience, we also want to make clear that each discussion sits within, and contributes to, a wider context of scholarship. Our intended audience includes students, academics, and members of the general public: analytics data do not reveal exactly who is listening, though informal feedback suggests that we attract a core number of dedicated listeners and a further number interested in the themes of particular episodes.

The problems accompanying the shift to online delivery should not be underestimated. We are aware of the issue of digital exclusion, whereby many people (including a large number of students) do not have access to the internet or to suitable devices. We are aware that it is difficult to replicate engaging, active learning sessions online, particularly when teaching sessions are recorded and not everyone is participating synchronously.

Given the constraints of our resources, the creation of a new podcast series seemed to us to represent an ethical and sustainable response to the COVID-19 crisis. Instead of putting our efforts into collecting new physical objects, the podcast enabled us to relate the museum's existing collections to current real-world concerns, and also to academic scholarship across disciplines. The podcast allowed us to take advantage of the digital medium, rather than trying to replicate an off-line experience inauthentically within online space. Episodes within season two have averaged around 60 downloads within the first week after broadcast; an average of around 100 downloads within the first month is regarded as the mark of a successful museum podcast (Hethmon 2018). The podcast 'That Feels Like Home' demonstrates our commitment 
to continuing to use the Museum of Domestic Design and Architecture's collections to support challenging discussions with a wide range of people, and it seems particularly apt when most of our listeners are in fact confined mostly at home.

Received: 29 June 2020

Finally accepted: 3 August 2020

\section{Notes}

1 www.moda.mdx.ac.uk, accessed 20 July 2020

2 See, for example, https://moda.mdx.ac.uk/conversations/picturing-world/, accessed 20 July 2020

3 https://moda.mdx.ac.uk/conversations/, accessed 20 July 202020

4 https://moda.mdx.ac.uk/conversations/home-work/, accessed 20 July 2020

5 'Ostens Servway: The Modern Service Hatch', catalogue by Ostens (Byfleet) Ltd, 19301940. BADDA1413. Museum of Domestic Design \& Architecture, Middlesex University, https://moda.mdx.ac.uk/object/badda1413/, accessed 20 July 2020.

6 'The One Maid Book of Cookery' by Mistress A. E. Congreve, 1913. BADDA2319. Museum of Domestic Design \& Architecture, Middlesex University, https://moda.mdx.ac.uk/object/ badda2319/, accessed 20 July 2020 .

\section{References}

Hethmon, H. (2018) Your Museum Needs a Podcast: A Step By Step Guide to Podcasting on a Budget for Museums, History Organizations, and Cultural Nonprofits, independently published.

\section{Author}

Zoe Hendon

ORCID iD: https://orcid.org/0000-0001-7083-7365

URL: http://www.moda.mdx.ac.uk

Museum of Domestic Design and Architecture

Middlesex University

United Kingdom

Z.Hendon@mdx.ac.uk

Zoe Hendon is Head of Collections at the Museum of Domestic Design and Architecture. Her research interests include the use of museum collections in Art and Design education. 